\title{
Pemanfaatan Limbah Plastik dan Kaca sebagai Pembuatan Bata Plastik yang Ramah Api
}

\author{
Harpito ${ }^{1}$, Ismu Kusumanto ${ }^{2}$, Yori Bunga Ananda ${ }^{3}$, Novirza $^{4}$, Silvia $^{5}$ \\ ${ }_{1,2,4,5)}$ Dosen Jurusan Teknik Industri, Fakultas Sains Dan Teknologi, Universitas Islam Negeri Sultan \\ Syarif Kasim Riau. \\ Jl. HR. Soebrantas No. 155 Simpang Baru, Panam, Pekanbaru, 28293 \\ E-mail: harpito@uin-suska.ac.id, ismu@uin-suska.ac.id \\ 3) Mahasiswi Jurusan Teknik Industri, Fakultas Sains Dan Teknologi, Universitas Islam Negeri Sultan \\ Syarif Kasim Riau. \\ Jl. HR. Soebrantas No. 155 Simpang Baru, Panam, Pekanbaru, 28293 \\ E-mail: yoribungananada@gmail.com
}

\begin{abstract}
In order to preserve the environment from plastic waste, various ways can be done, one solution is to make a brick made from plastic that is the secret fire and use glass as its mixture. Fire-friendly here using the distillation tool is done so that the oil content of the plastic is separate and the plastics produced are more friendly to the flame. The experimental design by using RAL was used to determine the composition of brick making. In determining the composition is fitting done with a test object, a cube-shaped test object with a size of $5 \times 5 \times 5 \mathrm{~cm}$. Maximum of absorbent brick power is $20 \%$, from the processing result then in the sample can be 4 th with water absorption of $0.74 \%$. Based on data processing, the total plastic weight for plastic bricks is $12.77 \%$. Then based on the observations that have been made known at a time 5 minutes 23 seconds. The bricks are not distilled, then the brick that has been distilled melted at a time of 17 minutes 40 seconds. Then based on the calculation result can be cost of raw materials amounting to Rp 51,000 , labor cost of $R p 38,461$, and the overhead variable fee is $R p 25,000$. So the total cost per day of $R p$ 114,461. Then based on 5\% margin, brick sale price of $R p 3,000 /$ seed and breakeven point determination or break event point plastic brick 43 seed, and the point of the scan is Rp 99,350.6493.
\end{abstract}

Keywords: Absorption Test, Break Event Point (BEP), Experimental Design, Complete Random Design (RAL), Cost of Product Production (HPP), Melting Point Testing.

\begin{abstract}
Abstrak
Dalam rangka menjaga kelestarian lingkungan dari limbah plastik berbagai cara dapat dilakukan, salah satu solusi yaitu dengan membuat bata yang berbahan plastik yang ramah api dan menggunakan kaca sebagai campurannya. Ramah api di sini menggunakan alat destilasi hal ini dilakukan agar kandungan minyak dari plastik terpisah dan plastik yang dihasilkan lebih ramah terhadap api. Metode yang digunakan yaitu desain eksperimen dengan menggunakan RAL untuk menentukan komposisi untuk pembuatan bata. Dalam menentukan komposisi yang pas dilakukan dengan benda uji, benda uji berbentuk kubus dengan ukuran $5 \times 5 \times 5 \mathrm{~cm}$. Maksimum daya serap bata yaitu $20 \%$, dari hasil pengolahan maka di dapat benda uji ke-4 memiliki daya serap air sebesar $0,74 \%$. Berdasarkan pengolahan data, total berat plastik untuk bata plastik yaitu 12,77 \%. Kemudian berdasarkan pengamatan yang telah dilakukan diketahui pada waktu 5 menit 23 detik bata yang tidak didestilasi meleleh, kemudian bata yang telah didestilasi meleleh pada waktu 17 menit 40 detik. Kemudian berdasarkan hasil perhitungan didapatlah biaya material sebesar Rp 51.000 , upah tenaga kerja sebesar Rp 38.461, dan biaya overhead variable yaitu Rp 25.000. Jadi total biaya per hari sebesar Rp 114.461. Maka berdasarkan margin 5\% maka didapatlah harga jual bata sebesar Rp 3.000/biji dan penentuan break event point (titik impas) bata plastik 43 biji, dan titik impasnya Rp 99.350,6493.
\end{abstract}

Kata kunci: Break Event Point (BEP), Desain Eksperimen, Harga Pokok Produksi (HPP), Pengujian Daya Serap, Pengujian Titik Leleh, Rancangan Acak Lengkap (RAL). 


\section{Pendahuluan}

Seiring dengan pesatnya perkembangan dunia industri, maka semakin tinggi pula produktivitas dalam pembuatan barang guna dalam rangka memenuhi kebutuhan hidup sehari-hari. Tak heran jika banyak industri di negara-negara berkembang maupun maju mencoba untuk mengembangkan atau menginovasi produknya menjadi sesuatu yang baru, termasuk negara Indonesia. Akan tetapi dampak yang di timbulkan akibat hal tersebut menjadi permasalahan yang serius yang harus diperhatikan yang mana permasalahan tersebut adalah permasalahan mengenai sampah.

Sampah iyalah suatu kesatuan yang telah melekat pada manusia. Setiap orang yang ada di bumi ini pasti menghasilkan sampah, hal yang mempengaruhi peningkatan sampah yaitu, semakin banyak yang di konsumsi manusia maka semakin banyak sampah yang ada, kemudian yang selanjutnya yaitu bertambahnya populasi penduduk. Akan tetapi sampah bukanlah sesuatu hal yang harus dibuang sepenuhnya. Karena sebagian sampah bisa di manfaatkan menjadi barang yang berguna dan menjadi nilai yang ekonomis. Limbah yang di hasilkan oleh sampah ini terdiri dari 2 jenis, yaitu organik dan non organik.

Limbah dari sampah organik adalah suatu limbah yang berasal dari sisa makhluk hidup yang terdapat di alam, seperti sisa makanan, sayuran, daun-daun kering, dan sebagainya. Sampah organik merupakan jenis sampah yang ramah lingkungan dan bahkan pada umumnya dapat dimanfaatkan kembali dengan melakukan pengolahan yang tepat seperti pupuk kompos dan berbagai macam makan ternak. Akan tetapi jika tidak di olah dengan baik dengan mengingat sifat dari sampah organik ini adalah membusuk maka hal ini dapat mengganggu kehidupan manusia. Kemudian limbah anorganik merupakan salah satu sumber masalah terbesar yang di temukan dalam kehidupan manusia karena sampah anorganik ini tidak dapat diurai dengan cepat, butuh waktu puluhan bahkan ratusan tahun agar bisa benar-benar terurai dengan baik. contoh dari limbah anorganik ini adalah kertas, plastik, gelas minuman, kaleng, kayu, kaca dan sebagainya (Marliani, 2014).
Permasalahan limbah ini terjadi di setiap wilayah Indonesia, terutama di wilayah kota Pekanbaru. Data sampah anorganik yang dihasilkan setiap tahunnya di kota Pekanbaru disajikan dalam Gambar 1.

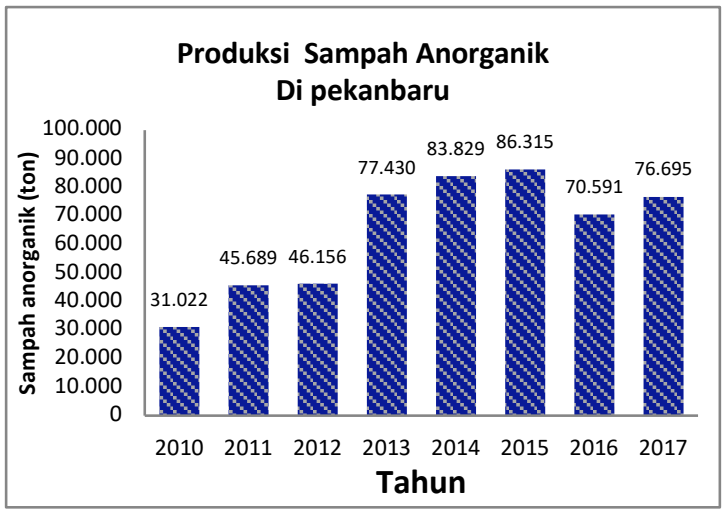

Gambar 1. Sampah anorganik di Pekanbaru

Berdasarkan Gambar 1 dapat terlihat bahwa sampah anorganik termasuk kategori sampah yang mengalami peningkatan sangat signifikan setiap tahunnya. Sampah anorganik ini perlu penanganan khusus agar tidak menjadi ancaman dalam kelestarian lingkungan. Maka dari itu untuk mengurang pencemaran, dilakukanlah tindakan yaitu dengan mendaur ulang sehingga menjadi barang yang berguna dan bernilai ekonomis.

Dalam rangka menjaga kelestarian lingkungan dari pencemaran sampah anorganik khususnya sampah plastik yang membahayakan berbagai upaya telah dilakukan pemerintah. Upaya-upaya yang telah dilakukan tersebut antara lain meminimalisir kantung plastik sebagai tempat belanjaan, menghimbau konsumen untuk membawa tas belanjaan sendiri, memanfaatkan sampah plastik sebagai bahan dasar berbagai kerajinan dan mensosialisasikan penggunaan plastik dan menjadikan barang yang mempunyai nilai ekonomi. Dalam penelitian ini kami menawarkan inovasi yaitu dengan membuat bata yang berbahan plastik. Pembangunan di Pekanbaru semakin meningkat. Maka penggunaan batu bata sebagai komponen utama sangat dibutuhkan dalam pembangunan. Komposisi pembuatan batu bata itu salah satunya yaitu pasir. Pasir merupakan salah satu sumber daya alam yang tidak dapat diperbarui. Dalam penelitian ini penggunaan pasir ditiadakan dan diganti dengan kaca sebagai campuran pembuatan 
bata. Limbah atau sampah kaca saat ini banyak di biarkan begitu saja. Jadi dalam penelitian ini untuk mengurangi limbah kaca tersebut maka di gunakanlah kaca sebagai campuran pengganti pasir dalam pembuatan batu bata yang berbahan dasar plastik.

Loria (2019) telah melakukan penelitian degan mencoba memanfaatkan sampah anorganik (plastik) sebagai bahan dasar bata selanjutnya Ardi (2016) melakukan kajian tentang dengan mengganti penggunaan pasir dengan serbuk kaca. Dalam penelitian ini juga dilakukan pengujian terhadap kekuatan, daya serap air dan densitas batu bata. Namun, Berdasarkan kedua penelitian tersebut, batu bata yang dihasilkan tidak tahan panas karena masih terdapat kandungan minyak pada plastik sehingga penggunaannya masih terbatas (Loria, 2019), batu bata yang dibuat masih menggunakan campuran pasir dan tanah liat sebagai komposisinya (Ardi, 2016).

Penelitian ini mengembangkan penelitian sebelumnya yaitu pembuatan batu bata dari limbah plastik yang ramah api dengan menggunakan campuran kaca. Batu bata yang berbahan plastik agar ramah api maka dilakukan penghilangan kandungan minyak dan kemudian menggunakan campuran kaca. Dengan penambahan kaca ini bertujuan untuk melestarikan lingkungan dengan menginovasi limbah-limbah kaca yang banyak berserakan sehingga menambah nilai guna dan menjadi barang yang bernilai jual.

\section{Metodologi}

Bagian ini memaparkan hasil tinjauan pustaka terkait dengan sampah, limbah kaca, batu bata, perancangan eksperimen; dan langkah-langkah penelitian.

\section{Tinjauan Pustaka \\ Sampah}

Sampah iyalah suatu permasalahan yang sering dihadapi oleh setiap warga disetiap warga negara. Hal ini berhubungan dengan faktor kebersihan, kesehatan, kenyamanan dan keindahan (estetika). Tumpukan onggokan sampah yang mengganggu kesehatan dan keindahan lingkungan merupakan jenis pencemaran yang dapat digolongkan dalam degradasi lingkungan yang bersifat sosial (Hasibuan, 2016).
Seiring dalam berkembangnya waktu manusia kurang sadar akan merawat lingkungannya sendiri. Banyak masyarakat yang mengerti akan kebersihan tetapi tidak diterapkan dalam kehidupan sehari-hari. Contohnya saja dalam aktivitas sehari-hari seperti pada saat kita mandi, mencuci, dan melakukan aktivitas lainnya yang di sering kita anggap sepele, tetapi hal tersebutlah yang ternyata dapat membahayakan bagi lingkungan. Dari sekian banyak aktivitas yang dilakukan oleh manusia, yang paling berbahaya yaitu limbah rumah tangga. Akibat penduduk di Indonesia yang memiliki populasi yang banyak di tambah kurangnya dalam pengolahan sampah maka akan berbahaya terhadap perairan dilaut yang kita cintai ini.

Purnawingrum (2016) mengemukakan bahwa Plastik merupakan material yang jika dipanaskan dengan suhu tertentu akan menjadi lunak dan plastis sehingga bisa dicetak dan dibentuk sesuai dengan keinginan. Berbagai produk yang terbuat dari plastik antara lain berbagai macam botol, pembungkus makanan, pipa, peralatan makan, dan lain-lain. Polimer dan zat aditif merupakan komposisi material campuran plastik.

Pada produk yang terbuat dari plastik biasanya disertai dengan logo yang dikenal dengan istilah simbol daur ulang. Adapun simbol yang sering digunakan dapat dilihat pada Tabel 1 berikut.

Tabel 1. Simbol daur ulang plastik

\begin{tabular}{|c|c|l|}
\hline No. & Simbol & \multicolumn{1}{|c|}{ Keterangan } \\
\hline 1. & PET/PETE & $\begin{array}{l}\text { Polyethylene Terephthalate } \\
\text { Dapat didaur ulang dengan } \\
\text { mudah (biodegradable) }\end{array}$ \\
\hline 2. & HDPE & $\begin{array}{l}\text { High Density Polyethylene } \\
\text { Dapat didaur ulang dengan } \\
\text { mudah (biodegradable) }\end{array}$ \\
\hline 3. & PVC/V & $\begin{array}{l}\text { Polyvinyl Chloride } \\
\text { Dapat didaur ulang dengan } \\
\text { mudah (biodegradable) }\end{array}$ \\
\hline 4. & LDPE & $\begin{array}{l}\text { Low Density Polyethylene } \\
\text { Susah didaur ulang }\end{array}$ \\
\hline 5. & PP & $\begin{array}{l}\text { Polypropylene } \\
\text { Titik leleh cukup tinggi, dapat } \\
\text { didaur ulang }\end{array}$ \\
\hline 6. & PS & $\begin{array}{l}\text { Polystyrene } \\
\text { Titik leleh tinggi, sulit didaur } \\
\text { ulang }\end{array}$ \\
\hline 7. & OTHER & $\begin{array}{l}\text { Polycarbonate } \\
\text { Titik leleh cukup tinggi, dapat } \\
\text { didur ulang }\end{array}$ \\
\hline
\end{tabular}


Gambar 2 menampilkan simbol-simbol/logo daur ulang seperti yang telah dijelaskan pada pada Tabel 1.

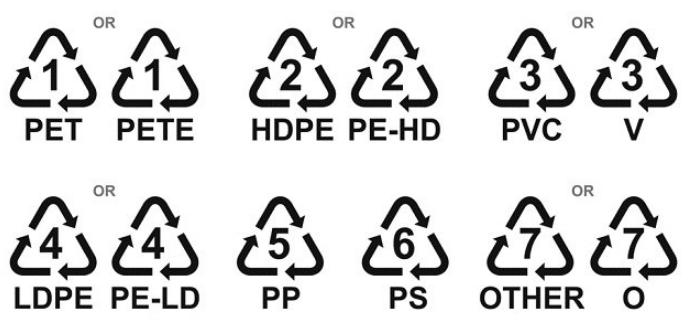

Gambar 2. Simbol daur ulang

\section{Limbah Kaca}

Kaca merupakan material yang padat bening dan transparan atau tembus pandang. Kaca ini berbahan dasar dari hasil beberapa peleburan yang kemudian didinginkan sampai fase padat (Justin, 2015).

Limbah kaca dapat kita temukan di berbagai tempat terutama pada industri yang menggunakan kaca sebagai bahan dasar produksinya. Misalnya, kita dapat menemukan limbah kaca di tempat produksi pintu, jendela dan partisi kaca, tempat produksi berbagai mebel seperti lemari kaca dan meja kaca serta bengkel kaca mobil.

Seperti halnya plastik, limbah kaca termasuk kategori sampah anorganik, sehingga tidak bisa terurai secara alami. Apabila limbah kaca dibuang sembarangan maka limbah tersebut kan merusak lingkungan dan bahkan dapat membahayakan jika serpihan kaca tersebut masuk ke dalam tubuh kita.

Kaca dapat meleleh pada suhu yang sangat tinggi, namun kaca juga dapat dihancurkan menjadi serbuk. Serbuk pecahan kaca inilah yang bisa dimanfaatkan sebagai bahan campuran pembuatan bata.

\section{Batu Bata}

Batu bata adalah bahan pembuat dinding yang paling banyak digunakan di Indonesia. Pada umumnya batu bata di buat dari tanah liat yang disebut dengan bata merah. Pada penelitian terdahulu rasio campuran tanah liat dengan limbah plastik dan limbah kaca adalah $5 \%, 10 \%$, dan $15 \%$.

Pengujian yang akan dilakukan berupa pengujian terhadap kekuatan batu bata antara lain compressive strength test, water absorption test, dan lain-lain yang berhubungan dengan kekuatan batu bata (As et al., 2017).

Adapun jenis-jenis batu bata yang sering kita jumpai adalah sebagai berikut (Prayuda et al., 2018):

Tabel 2. Jenis-Jenis batu bata

\begin{tabular}{|l|l|l|}
\hline \multicolumn{1}{|c|}{ Jenis } & \multicolumn{1}{c|}{ Bahan Baku } & Penggunaan \\
\hline $\begin{array}{l}\text { Bata } \\
\text { Merah }\end{array}$ & $\begin{array}{l}\text { Tanah Liat dan Air } \\
\text { yang dibakar } \\
\text { sampai warna } \\
\text { kemerahan }\end{array}$ & Dinding/Tembok \\
\hline Batako & $\begin{array}{l}\text { Pasir, Semen dan } \\
\text { Air yang dicetak } \\
\text { dengan cetakan } \\
\text { khusus }\end{array}$ & Dinding/Tembok \\
\hline $\begin{array}{l}\text { Paving } \\
\text { Block }\end{array}$ & $\begin{array}{l}\text { Pasir, Semen dan } \\
\text { Air } \pm \text { bahan lain } \\
\text { yang dicetak } \\
\text { dengan cetakan } \\
\text { khusus }\end{array}$ & Lantai Parkir \\
\hline
\end{tabular}

\section{Water Absorption Test}

Water Absorption Test dikenal juga dengan istilah pengujian daya serap air. Water Absorption test digunakan untuk mengetahui sejauh mana kemampuan suatu bahan untuk dapat menghisap air. Tinggi rendahnya kemampuan hisap air suatu bahan dipengaruhi oleh besar kecilnya pori dari bahan tersebut. Jika batu bata memiliki Water Absorption yang tinggi maka dapat mempengaruhi kualitas pemasangan batu bata. Sebab batu bata tersebut akan mampu menyerap air semen dan bahkan air hujan yang mengenainya. (Umar, 2017).

$$
\text { Penyerapan Air }(\%)=\frac{M b-M k}{M k} \times 100 \% \quad \text { Pers. } 1
$$

Keterangan:

$\mathrm{Mb}$ : Berat Basah (gr)

Mk : Berat Kering (gr)

\section{Uji Kelelehan}

Pengujian kelelehan digunakan untuk menentukan waktu kapan suatu material atau benda mulai meleleh dan berubah dari padat menjadi cair hingga menjadi cari sempurna. Pengujian kelelehan dilakukan dalam suatu rangkaian percobaan dengan membakar benda uji pada tungku berapi konstan pada suhu tertentu. Pengamatan dilakukan terhadap perubahan bentuk benda uji akibat pembakaran. 


\section{Tekno Ekonomi}

Permodelan tekno ekonomi merupakan salah satu kaidah yang dapat dimanfaatkan dalam menilai kelaikan ekonomi dari berbaikan aspek teknis yang komprehensif. Salah satu faktor yang amat penting dalam tekno ekonomi adalah biaya (cost). Cost merupakan sejumlah uang yang harus dikeluarkan atau dibayarkan dalam rangka untuk memenuhi kebutuhan oleh individu ataupun kelompok orang terhadap suatu barang atau jasa dengan harapan dapat mendatangkan keuntungan. Dalam hal produksi, cost merupakan seluruh pengeluaran dalam satuan mata uang dalam rangka memenuhi kebutuhan proses produksi.

$T_{c}=$ Material Cost + Labour Cost Pers. 2

Tc : Total Cost

Material Cost : Biaya Bahan Baku Labour Cost : Biaya Tenaga Kerja

$$
\text { BTK }=\frac{\text { Waktu Pembuatan Produk }}{\text { Jam Kerja }} x \text { Upah Pers. } 3
$$

Titik Impas atau Break Even Point (BEP) merupakan suatu metode yang digunakan dalam rangka mengetahui kondisi di mana suatu usaha yang dilakukan dapat menyamakan antara total biaya dan total pendapatan.

$$
\begin{aligned}
& B E P_{\text {Unit }}=\frac{\text { Fix Cost }(\mathrm{F})}{\text { Harga Unit }(\mathrm{P}) \text {-Variabel Unit }(\mathrm{V})} \quad \text { Pers. } 4 \\
& B E P_{R p}=\frac{\text { Fix Cost }(\mathrm{F})}{1-\frac{\text { Biaya Variabel Unit }(\mathrm{V})}{\text { Fix Cost }(\mathrm{F})}} \quad \text { Pers. } 5
\end{aligned}
$$

\section{Destilasi}

Destilasi pada dasarnya adalah proses pemisahan suatu campuran menjadi dua atau lebih produk, lewat eksploitasi perbedaan kemampuan menguap komponen-komponen dalam campuran. Dalam kata lain destilasi adalah suatu cara pemisahan larutan dengan menggunakan panas sebagai pemisah (separating agent). Proses ini dilakukan di dalam suatu kolom baki (tray column) atau kolom dengan isian (packing column), sehingga dapat terjadi kerja pemisahan yang lebih baik. Umumnya metode destilasi digunakan untuk memisahkan komponenkomponen dari suatu larutan. Ada beberapa metode destilasi yang sering digunakan dalam industri yakni (Arwizet, 2017):

1. Destilasi kilat (flash destillation) dan kondensasi parsial.

2. Destilasi sederhana (simple destillation).

3. Destilasi uap (steam destillation).

4. Distilasi kilat (flash) dan kondensasi parsial.

\section{Rancangan Acak Lengkap (RAL)}

RAL merupakan rancangan yang paling sederhana di antara rancangan-rancangan percobaan yang lain. Dalam rancangan ini perlakuan dikenakan sepenuhnya secara acak terhadap satuan-satuan percobaan atau sebaliknya. Pola ini dikenal sebagai pengacakan lengkap atau pengacakan tanpa pembatasan. Penerapan percobaan satu faktor dalam RAL biasanya digunakan jika kondisi satuan-satuan percobaan relatif homogen.

Pengujian dengan analisis Rancangan Acak Lengkap (RAL) sebagai berikut:

1. Menentukan hipotesis

Hipotesis merupakan asumsi jawaban yang bersifat sementara berdasarkan pada hasil studi sebelum percobaan dilakukan. Hipotesis biasanya memuat pernyataanpernyataan yang bersifat netral atau hal yang umum terjadi. $\mathrm{H} 0: \tau 1=\ldots=\tau i=0$ (tidak ada pengaruh perlakukan terhadap respons yang diamati) $\mathrm{H} 1$ : setidaknya ada satu i di mana $\tau i \neq 0$.

2. Pengacakan

Pengacakan merupakan proses yang dilakukan agar masing-masing satuan percobaan memiliki probabilitas yang sama untuk diberi perlakuan tertentu. Pengacakan bisa dilakukan dengan menggunakan tabel bilangan acak, sistem lotre secara manual atau dapat juga menggunakan komputer. Tabel 3 dapat digunakan untuk mencatat data

\begin{tabular}{|c|c|c|c|c|c|}
\hline \multirow[t]{2}{*}{ Ulangan } & \multicolumn{4}{|c|}{ Perlakuan } & \multirow{5}{*}{ Total } \\
\hline & P1 & P2 & $\ldots .$. & $\mathbf{P i}$ & \\
\hline 1 & $\mathrm{Y}_{11}$ & $Y_{21}$ & & $\mathrm{Y}_{\mathrm{i} 1}$ & \\
\hline 2 & $Y_{12}$ & $Y_{22}$ & & $\mathrm{Y}_{\mathrm{i} 2}$ & \\
\hline$\ldots \ldots$ & $\ldots .$. & & & & \\
\hline $\mathrm{J}$ & $\mathrm{Y}_{1 \mathrm{j}}$ & $\mathrm{Y}_{2 \mathrm{j}}$ & $\ldots .$. & $Y_{i j \ldots} \ldots$ & $Y$ \\
\hline Total (Yi..) & $Y_{1} \ldots$ & $Y_{2 \ldots}$ & $\ldots .$. & $Y_{i} \ldots$ & Y... \\
\hline
\end{tabular}
pengamatan RAL.

Tabel 3. Pengamatan untuk RAL 
a. Menghitung Faktor Koreksi (FK).

$$
F K=\frac{(T i j)^{2}}{r \times t}
$$

Pers. 6

Keterangan:

$\mathrm{T}_{\mathrm{ij}}$ = jumlah total data

$r$ = Banyaknya pengulangan

$\mathrm{t}$ = Banyaknya perlakuan

b. Menghitung Jumlah Kuadrat Total (JKT).

$$
\begin{aligned}
\mathrm{JKT} & =\mathrm{T}(\mathrm{Tij} 2)-\mathrm{FK} \\
& =\sum_{i=1}^{t} \quad \sum_{j=1}^{r i} Y i j-F K \quad \text { Pers. } 7
\end{aligned}
$$

Keterangan:

$Y_{i j}=$ data untuk setiap perlakuan pada setiap ulangan.

c. Menghitung Jumlah Kuadrat Perlakuan (JKP).

$$
J K P=\sum \text { ryi2 }-F K
$$

Pers. 8

d. Menghitung Jumlah Kuadrat Galat (JKG).

$$
J K G=J K T-J K F
$$

Pers. 9

e. Menghitung Kuadrat Tengah Perlakuan (KTP).

$$
\mathrm{KTP}=\frac{\mathrm{JKP}}{t-1}
$$

Pers. 10

f. Menghitung Kuadrat Tengah Galat (KTG).

$$
\mathrm{KTG}=\frac{\mathrm{KTP}}{\mathrm{KTG}}
$$

Pers. 11

\section{g. Analisa dan Kesimpulan}

Setelah dilakukan perhitungan di atas, akan didapatkan tabel secara lengkap seperti pada Tabel 4.

Statistik uji $F_{\text {hitung }}=\mathrm{KTP} / \mathrm{KTG}$ mengikuti sebaran $F$ dengan derajat bebas pembilang sebesar $\mathrm{t}-1$ dan derajat bebas penyebut sebesar $t(r-1)$. Dengan demikian jika nilai $F$ hitung lebih besar dari $F_{\alpha, d b 1}$, db2 maka hipotesis nol ditolak dan berlaku sebaliknya.

\section{Tahapan Penelitian}

Berikut diuraikan tahapan-tahapan yang dilakukan dalam penelitian ini, yaitu sebagai berikut:

Pengumpulan data yang terdiri dari data primer dan data sekunder.

1. Data primer

Data primer yaitu data yang merupakan hasil dari pengamatan dan wawancara secara langsung. Data primer yang didapatkan dalam penelitian ini adalah:

a. Kebutuhan limbah plastik dan kaca

b. Kebutuhan biaya produksi bata plastik

2. Data sekunder

Data sekunder merupakan data pendukung yaitu data yang diperoleh melalui dokumendokumen dan arsip resmi. Data sekunder dalam penelitian ini adalah banyaknya produksi sampah anorganik di Kota Pekanbaru dari tahun 2010 s.d tahun 2017.

Setelah semua data yang dibutuhkan didapatkan, maka selanjutnya dilakukan pengolahan data. Pengolahan data dilakukan dengan teknik dan metode yang telah ditetapkan. Adapun teknik dan langkahlangkah pengolahan data yang dilakukan adalah sebagai berikut:

1. Desain eksperimen.

Agar dapat menghasilkan bata yang memiliki kualitas tinggi dengan komposisi yang optimal, maka percobaan harus dilakukan berulang kali. Percobaan dilakukan terhadap variasi komposisi sebagai variabel kriterium (terikat) dalam penelitian ini.

Dalam penelitian ini dilakukan 6 kali percobaan dengan komposisi berbeda dan 2 perlakuan yang mana 3 kali percobaan pada kondisi pertama dan 3 kali percobaan pada kondisi kedua. Hal yang berguna untuk mengetahui apakah ada pengaruh campuran kaca yang digunakan dalam pembuatan bata pada saat uji bakar. Adapun perlakukannya yaitu bata dengan campuran kaca dan bata tanpa campuran kaca.

Berikut diuraikan prosedur perhitungan,

a. Asumsi dan hipotesis

b. Model Linier dan Analisa Ragam

1) Hitung Faktor Koreksi (FK)

2) Hitung Jumlah Kuadrat Total (JKT)

3) Hitung Jumlah Kuadrat Perlakuan (JKP)

4) Hitung Jumlah Kuadrat Galat (JKG) 
Tabel 4. Tabel model Rancangan Acak Lengkap (RAL)

\begin{tabular}{|l|c|c|c|c|c|}
\hline $\begin{array}{c}\text { Sumber } \\
\text { keragaman }\end{array}$ & Derajat bebas & Jumlah kuadrat & Kuadrat tengah & F & $F_{\text {hitung }}$ \\
\hline Perlakuan & $\alpha-1$ & JKP & KTP & KTP/KTG & F $\alpha(\mathrm{t}-1, \mathrm{t}(\mathrm{r}-1))$ \\
\hline Galat & $\alpha(\mathrm{b}-1)$ & JKG & KTG & & \\
\hline Total & Ab-1 & JKT & & & \\
\hline
\end{tabular}

5) Hitung Kuadrat Tengah Perlakuan (KTP)

6) Hitung Kuadrat Tengah Galat (KTG)

7) Analisis dan kesimpulan

\section{Uji Daya Serap Air}

Pengujian daya serap air dilakukan untuk mengetahui seberapa besar kemampuan bata plastik untuk dapat menyerap air. Bata dengan kualitas yang baik memiliki daya serap air $<20 \%$.

Prosedur uji daya serap air bata plastik yang dilakukan adalah sebagai berikut:

a. Siapkan bata plastik, timbangan, bejana dan wadah yang berisi air:

b. Lakukan penimbangan terhadap bata plastik dalam kondisi kering mutlak (didapatkan Wk).

c. Masukkan bata plastik ke dalam wadah berisi air hingga seluruh bagian bata plastik terendam sampai tidak ada lagi gelembung udara yang keluar dari pori bata plastik.

d. Lakukan penimbangan terhadap bata plastik dalam keadaan basah jenuh (didapatkan Wb).

e. Hitung daya serap air dengan menggunakan Pers 1.

\section{Analisis Tekno Ekonomi}

Analisa Tekno Ekonomi yang dilakukan berupa perhitungan Harga Pokok Produksi (HPP) dan perhitungan Titik Impas (Break Event Point/BEP).

Variabel yang mempengaruhi HPP adalah sebagai berikut:

- Biaya bahan baku

- Upah tenaga kerja

- Biaya tak terduga (overhead)

Dari HPP yang didapatkan maka dapat kita tentukan harga jual produk tersebut. Berdasarkan harga jual produk tersebut, maka selanjutnya kita dapat menghitung titik impas (BEP) dalam bentuk unit dan harga dengan menggunakan rumus yang ada pada Pers. 4 dan Pers. 5.

\section{Hasil dan Diskusi}

Dalam pembuatan bata plastik ada beberapa tahap yang harus dilalui, yaitu:

1. Persiapkan bahan baku berupa sampah plastik dan limbah kaca sesuai dengan kebutuhan.

2. Lakukan Proses destilasi dengan cara memasukkan sampah plastik ke dalam alat destilasi, nyalakan api kompor kemudian tunggu hingga uap penyulingannya keluar melalui selang yang di alirkan ke dalam ember berisi air dingin untuk mengubah uap menjadi minyak sehingga minyak terpisah dari plastik dan tersisa endapan plastik atau ampas dari sisa penyulingan.

3. Tunggu hingga 100 menit sampai 120 menit agar plastik berubah menjadi pasta plastik dan minyak mulai keluar dari kondensor alat destilasi. Sambil menunggu proses destilasi selesai, lakukan penumbukan terhadap kaca hingga halus, dan untuk mendapatkan serbuk kaca yang halus lakukan pengayakan.

4. Persiapkan cetakan. Permukaan cetakan dioleskan minyak pelumas (oli) untuk menghindari terjadinya adhesi antara bahan bata dan cetakan, sehingga bata tidak lengket dengan cetakan .

5. Setelah proses destilasi selesai campurkan endapan plastik dengan serbuk kaca dan aduk sampai merata

6. Tuangkan adonan ke dalam cetakan. Kemudian tutup hingga rapat cetakan dan pres.

7. Diamkan adonan dalam cetakan selama kurang lebih 30 sampai 50 menit.

8. Buka cetakan dan keluarkan bata dari cetakan. 


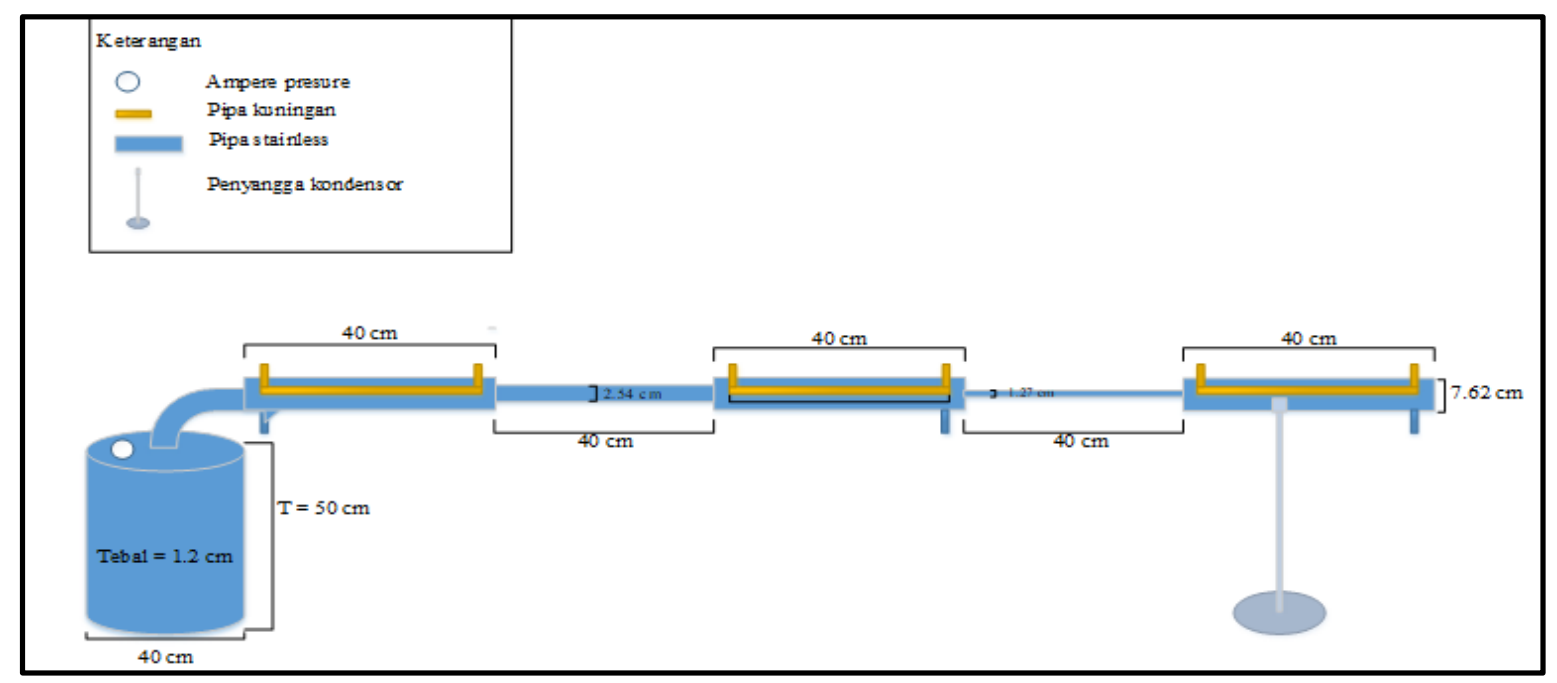

Gambar 3. Alat destilasi

Dalam penelitian pembuatan bata plastik ini menggunakan metode desain eksperimen dengan penggunaan Rancangan Acak Lengkap (RAL). Dalam perhitungan Rancangan Acak Lengkap ini yaitu menggunakan data berat limbah kaca yang telah dihaluskan, berat plastik, berat benda uji, berat basah dan berat kering bata plastik. Pada pembuatan bata plastik ini, langkah awal yang dilakukan adalah membuat benda uji. Benda uji merupakan media yang digunakan dalam menemukan dan menyelidiki komposisi sampah plastik dan limbah kaca yang optimal. Bentuk geometri benda uji yang digunakan dalam penelitian ini adalah berupa kubus sebanyak 5 buah yang berukuran $5 \times 5 \times 5 \mathrm{~cm}$.. Maka dapat diperoleh data seperti pada Tabel 3.

Tabel 3. Data pendahuluan

\begin{tabular}{|c|c|c|c|c|}
\hline No & Plastik & Kaca & $\begin{array}{c}\text { Berat } \\
\text { Kering }\end{array}$ & $\begin{array}{c}\text { Berat } \\
\text { Basah }\end{array}$ \\
\hline 1 & 150 & 0 & 110 & 111 \\
\hline 2 & 160 & 0 & 115 & 116 \\
\hline 3 & 170 & 0 & 120 & 121 \\
\hline 4 & 250 & 50 & 135 & 136 \\
\hline 5 & 280 & 50 & 150 & 152 \\
\hline 6 & 300 & 50 & 185 & 188 \\
\hline
\end{tabular}

Setelah benda uji selesai dicetak, selanjutnya dilakukan pengujian pertama yang dilakukan adalah Water Absorption test untuk mengetahui sejauh mana kemampuan bata plastik untuk dapat menghisap air. Berdasarkan Standar Nasional Indonesia (SNI) 16-2094-2000, bata yang baik memiliki kemampuan menyerap air tidak lebih dari $20 \%$.
Langkah-langkah pengujian Water Absorption bata plastik dapat diuraikan sebagai berikut:

1. Peralatan yang harus disediakan antara lain adalah benda uji, timbangan, Wadah perendaman serta kertas dan alat tulis

2. Lakukan penimbangan terhadap benda uji yang masih dalam keadaan kering dan catat sebagai Mk.

3. Benda uji selanjutnya direndam dalam wadah berisi air hingga semua permukaan terendam.

4. Diam kan beberapa saat hingga semua pori terisi air yang ditandai dengan tidak adanya gelembung udara yang muncul.

5. Setelah benar-benar yakin benda uji sudah dalam keadaan jenuh air, timbang benda uji dalam keadaan basah dan catat sebagai $\mathrm{Mb}$.

6. Setelah pengujian selesai dilakukan, hitung penyerapan air dengan menggunakan Pers.1.

Data hasil uji daya penyerapan air pada bata plastik dengan campuran serbuk kaca disajikan pada Tabel 4.

Tabel 4. Hasil pengujian daya serap air bata plastik

\begin{tabular}{|c|c|c|c|}
\hline $\begin{array}{c}\text { Sampel } \\
\text { Ke- }\end{array}$ & $\begin{array}{c}\text { Berat } \\
\text { Basah } \\
\text { (mb) }\end{array}$ & $\begin{array}{c}\text { Berat } \\
\text { Kering } \\
\text { (mk) }\end{array}$ & Daya Serap (\%) \\
\hline 1 & 111 & 110 & 0,90 \\
\hline 2 & 116 & 115 & 0,86 \\
\hline 3 & 121 & 120 & 0,83 \\
\hline 4 & 136 & 135 & 0,74 \\
\hline 5 & 152 & 150 & 1,33 \\
\hline 6 & 188 & 185 & 1,62 \\
\hline
\end{tabular}


Gambar 4 merupakan grafik yang diperoleh berdasarkan pengolahan yang telah dilakukan.

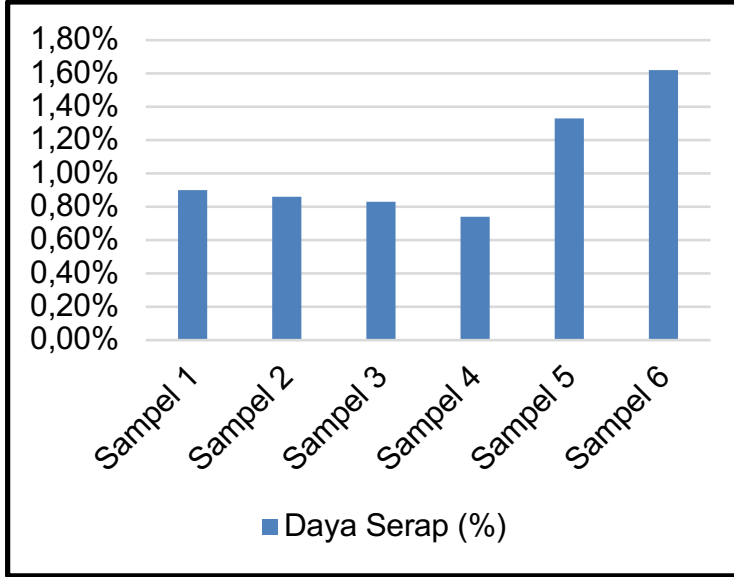

Gambar 4. Grafik water absorption

Tabel 5 dan 6 menyajikan data perhitungan uji hipotesis untuk daya serap bata plastik dengan tiga kali pengulangan.

Tabel 5. Perhitungan pengujian hipotesis

\begin{tabular}{|l|c|c|c|c|c|}
\hline \multirow{2}{*}{ Perlakuan } & \multicolumn{3}{|c|}{ Pengulangan } & \multirow{2}{*}{ Total } & $\begin{array}{c}\text { Rata- } \\
\text { rata }\end{array}$ \\
\cline { 2 - 4 } & $\mathbf{1}$ & $\mathbf{2}$ & $\mathbf{3}$ & & 0,86 \\
\hline $\begin{array}{l}\text { Plastik } \\
100 \%\end{array}$ & 0,90 & 0,86 & 0,83 & 2,59 & 0,23 \\
\hline $\begin{array}{l}\text { Plastik + } \\
\text { Kaca }\end{array}$ & 0,74 & 1,33 & 1,62 & 3,69 & 1,23 \\
\hline Jumlah & 1,64 & 2,19 & 3,45 & 6,28 & \\
\hline \multicolumn{7}{|l}{ Rata-Rata Umum } \\
\hline
\end{tabular}

Tabel 6. Analisis ragam

\begin{tabular}{|l|l|l|l|l|l|l|}
\hline \multirow{2}{*}{ Sumber } & \multirow{2}{*}{ Db } & \multirow{2}{*}{ JK } & \multirow{2}{*}{ KT } & \multirow{2}{*}{$\mathbf{F}_{\text {hitung }}$} & \multicolumn{2}{|c|}{$\mathbf{F}_{\text {tabel }}$} \\
\cline { 6 - 7 } & & & & & $\boldsymbol{\alpha}=\mathbf{5 \%}$ & $\boldsymbol{\alpha}=\mathbf{1 \%}$ \\
\hline Perlakuan & 1 & 0,202 & 0,202 & 1,993 & 7,71 & 21,20 \\
\hline Galat & 4 & 0,405 & 0,101 & & & \\
\hline Total & 5 & 0,606 & & & & \\
\hline
\end{tabular}

Berdasarkan perhitungan dapat disimpulkan bahwa Water Absorption test bata plastik dengan campuran serbuk kaca telah memenuhi kriteria yang disyaratkan oleh SNI yaitu kecil dari $20 \%$. Berdasarkan tabel 6 , didapatkan Fhitung $(1,993)<F_{\text {tabel }}(7,71$, sehingga $\mathrm{H}_{0}$ diterima dan $\mathrm{H}_{1}$ ditolak.

Dalam pengujian kelelehan bata ini yaitu menggunakan tungku sebagai alat untuk membakar bata. Pada pengujian ini juga menggunakan stopwatch sebagai alat penghitung waktunya. Jadi dengan menggunakan stopwatch maka perbandingan waktu antara sampel-sampel bata yang telah dibuat sebelumnya. Pada pengujian ini dibuat sampel dengan campuran yang mirip dengan bata yang komposisi campuran bata dan keramik optimal saat dilakukan uji daya serap. Berdasarkan hasil pengamatan bata yang belum didestilasi atau bata yang non destilasi telah meleleh pada waktu 5 menit 23 detik. Batu bata yang didestilasi meleleh pada waktu 17 menit 40 detik.

Penentuan harga jual bata plastik digunakan acuan dari HPP yang didapatkan dari perhitungan. Pada penelitian ini diasumsikan bata plastik yang diproduksi sebanyak 40 biji per hari dengan tenaga kerja hanya 1 orang. Total biaya yang dibutuhkan dalam membuat bata plastik dengan campuran serbuk kaca disajikan dalam tabel 7 berikut;

Tabel 7. Rekapitulasi biaya variabel

\begin{tabular}{|c|l|r|}
\hline No & \multicolumn{1}{|c|}{ Variable Costing } & \multicolumn{1}{c|}{ Harga Per Hari } \\
\hline 1 & Biaya bahan baku & $\mathrm{Rp} 51.000$ \\
\hline 2 & Biaya tenaga kerja & $\mathrm{Rp} 38.461$ \\
\hline 3 & Biaya overhead & $\mathrm{Rp} 25.000$ \\
\hline \multicolumn{2}{r|}{ Total } & $\mathbf{R p ~ 1 1 4 . 4 6 1}$ \\
\hline
\end{tabular}

Perhitungan HPP bata plastik dengan campuran serbuk kaca adalah sebagai berikut;

$$
\begin{aligned}
H P P(\text { unit }) & =\frac{\text { Total Cost }}{\text { Jumlah yang Diproduksi }} \\
= & \frac{\text { Rp } 114.461}{40 \mathrm{Biji}} \\
= & \operatorname{Rp} 2.861 / \mathrm{biji} \approx \operatorname{Rp} 2.900 / \mathrm{biji}
\end{aligned}
$$

Harga jual yang ditawarkan ke konsumen menggunakan margin sebesar $5 \%$, di mana bata plastik ini termasuk produk yang baru diproduksi sehingga harga jual yang ditawarkan jauh lebih murah dibandingkan harga di pasaran yang berkisar Rp 900/biji untuk bata merah dan 3500/biji untuk batako atau bata semen. Berikut ini adalah perhitungan harga jual.

Harga Jual

$$
\begin{aligned}
& =\frac{\text { Total Biaya }+ \text { Laba yang diharapkan }}{\text { Total Produksi }} \\
& =\frac{\operatorname{Rp} 114.461+(5 \% \times \mathrm{Rp} 114.461)}{40 \mathrm{Biji}} \\
& =\frac{\operatorname{Rp} 114.461+(\mathrm{Rp} 5723,05)}{40 \mathrm{Biji}} \\
& =\frac{\operatorname{Rp} 129.184,05}{40 \mathrm{Biji}} \approx \mathrm{Rp} 3.000 / \mathrm{biji}
\end{aligned}
$$


Tabel 8 menampilkan perhitungan depresiasi peralatan.

Tabel 8. Rekapitulasi biaya dan alat pembuatan bata plastik

\begin{tabular}{|l|l|c|c|c|c|}
\hline No & Uraian & Jml & $\begin{array}{c}\text { Harga } \\
\text { awal } \\
\text { (Rp.) }\end{array}$ & $\begin{array}{c}\text { Masa } \\
\text { pakai } \\
\text { (tahun) }\end{array}$ & $\begin{array}{c}\text { Depr. } \\
\text { (Rp.) }\end{array}$ \\
\hline 1 & Timbangan & 1 & 75.000 & 3 & 25.000 \\
\hline 2 & $\begin{array}{l}\text { Kompor } \\
\text { Gas }\end{array}$ & 1 & 125.000 & 5 & 25.000 \\
\hline 3 & $\begin{array}{l}\text { Wadah } \\
\text { Pemanasan }\end{array}$ & 1 & 1.000 & 1 & 1.000 \\
\hline 4 & Pengaduk & 1 & 3.000 & 1 & 3.000 \\
\hline 5 & Cetakan & 1 & 112.500 & 5 & 22.500 \\
\hline \multicolumn{5}{|c|}{ Total } \\
\hline
\end{tabular}

Adapun rekapitulasi biaya-biaya yang dikeluarkan pada pembuatan bata plastik dengan campuran serbuk kaca dapat dilihat pada Tabel 9 . Setelah semua biaya didapat, Selanjutnya menghitung titik impas (BEP). Perhitungan BEP dilakukan sesuai dengan Pers 4 dan Pers.

$$
\begin{aligned}
B E P_{\text {Unit }} & =\frac{\mathrm{Fix} \text { Cost }(\mathrm{F})}{\text { Harga Unit }(\mathrm{P})-\text { Variabel Unit }(\mathrm{V})} \\
& =\frac{\text { Rp. } 76.500}{\operatorname{Rp} .3 .100-\text { Rp. } 1.300} \\
& =\frac{\operatorname{Rp} 76.500}{\operatorname{Rp} 1.800} \\
& =42,5 \approx 43 \mathrm{biji} \\
B E P_{R p} & =\frac{\text { Fix Cost }(\mathrm{F})}{1-\frac{\text { Biaya Variabel Unit }(\mathrm{V})}{\text { Fix Cost }(\mathrm{F})}} \\
& =\frac{\text { Rp. } 76.500}{1-\frac{\text { Rp. } 114.461}{\text { Rp. } 124.000}} \\
& =\frac{\text { Rp. } 76.500}{1-0,9230} \\
& =\frac{\text { Rp.76.500 }}{0,077} \\
& =\text { Rp } 99.350,6493
\end{aligned}
$$

Tabel 9. Rekapitulasi Biaya

\begin{tabular}{|c|l|l|c|}
\hline \multirow{2}{*}{ No } & \multicolumn{2}{|c|}{ Jenis Biaya } & Harga Perhari \\
\hline \multirow{2}{*}{1} & \multirow{2}{*}{$\begin{array}{l}\text { Biaya } \\
\text { var. }\end{array}$} & Biaya bahan baku & Rp 51.000 \\
\cline { 3 - 4 } & & Biaya tenaga kerja & $\mathrm{Rp} \mathrm{38.461}$ \\
\cline { 3 - 4 } & Biaya overhead variable & $\mathrm{Rp} \mathrm{25.000}$ \\
\cline { 3 - 4 } 2 & $\begin{array}{l}\text { Biaya } \\
\text { tetap }\end{array}$ & Dotal & Rp 114.461 \\
\hline \multicolumn{2}{|c|}{ Total Keseluruhan } & Rp 76.500 \\
\hline \multicolumn{2}{|c|}{ Rp 190.961 } \\
\hline
\end{tabular}

\section{Kesimpulan}

Hasil pengujian kelelehan memperlihatkan bahwa bata plastik yang didestilasi dengan menggunakan campuran pecahan kaca tetap akan meleleh pada watu 17 menit 40 detik. saat dibakar, namun tidak sampai meleleh sempurna sebagaimana halnya bata plastik tanpa destilasii.

Campuran komposisi optimal bata plastik dengan serbut kaca terdapat pada sampel nomor 4 di mana sampel ini memiliki Water Absorption sebesar $0,74 \%$ dengan komposisi berat plastik 250 gram dan pecahan kaca 50 gram.

Harga jual bata per biji didapatkan sebesar Rp 3.000, dengan titik impas per unitnya 43 biji dan titik impasnya harganya berada pada angka $\operatorname{Rp} 99.350,6483$

Untuk meningkatkan kualitas penelitian selanjutnya disarankan:

1. Melakukan pengujian kuat tekan untuk mendapatkan komposisi campuran yang lebih optimal dengan kualitas terbaik.

2. Variasi komposisi sampel dibuat lebih banyak agar data yang diperoleh lebih akurat.

3. Mempertimbangkan bentuk geometrik bata plastik agar bata plastik mudah di aplikasikan pada pasangan dinding.

\section{Daftar Pustaka}

Ardi, A. W. (2016). Uji Kuat Tekan, Daya Serap Air dan Identitas Material Batu Bata dengan Penambahan Agregat Limbah Botol Kaca (Doctoral dissertation, Universitas Islam Negeri Alauddin Makassar).

Arwizet, A. (2017). Mesin Destilasi Pengolahan Sampah Plastik Menjadi Bahan Bakar Minyak Menggunakan Kondensor Bertingkat Dan Pendingin Kompresi Uap. INVOTEK: Jurnal Inovasi Vokasional dan Teknologi, 17(2), 75-88.

As, F. K., Novareza, O., \& Santoso, P. B. (2017). Peningkatan Kualitas Produk Batu Bata Merah Dengan Memanfaatkan Limbah Abu Serat Sabut Kelapa Dan Abu Serbuk Gergaji.

Hasibuan, R. (2016). Analisis dampak limbah/sampah rumah tangga terhadap pencemaran lingkungan hidup. Jurnal IImiah Advokasi, 4(1), 42-52.

Justin, J., Sadika, F., \& Sufyan, A. (2015). Eksplorasi Limbah Kaca Studi Kasus 
Industri Mebel. eProceedings of Art \& Design, 2(2).

Loria, D. P. (2019). Analisis Tekno Ekonomi Pengelolaan Sampah Plastik Sebagai Bahan Baku Pembuatan Bata, Universitas Islam Negeri Sultan Syarif Kasim Riau.

Marliani, N. (2015). Pemanfaatan limbah rumah tangga (sampah anorganik) sebagai bentuk implementasi dari pendidikan lingkungan hidup. Formatif: Jurnal IImiah Pendidikan MIPA, 4(2).

Prayuda, H., Setyawan, E. A., \& Saleh, F. (2018). ANALISIS SIFAT FISIK DAN MEKANIK BATU BATA MERAH DI
YOGYAKARTA (Analysis Physical and mechanical attributes of masonry in Yogyakarta). Jurnal Riset Rekayasa Sipil, 1(2), 94-104.

Purwaningrum, P. (2016). Upaya mengurangi timbulan sampah plastik di lingkungan. Indonesian Journal of Urban and Environmental Technology, 8(2), 141147.

Umar, M. Z. (2017, April). Daya Serap Air Batako Beton Dari Bahan Pasir Pohara Dan Nambo. In Seminar on Applied Quantitative Research. 
DOI: https://doi.org/10.26593/jrsi.v10i1.3995.101-112

Halaman ini sengaja dikosongkan.

This page is intentionally left blank. 